\title{
Irish consumers' use and perception of nutrition and health claims
}

\author{
Ann-Marie Lynam ${ }^{1, *}+$, Aideen McKevitt ${ }^{2}$ and Michael J Gibney ${ }^{2}$ \\ ${ }^{1} \mathrm{NICHE}$, School of Biomedical Sciences, University of Ulster, Coleraine, Northern Ireland: ${ }^{2}$ Institute of Food \\ and Health, School of Agriculture, Food Science and Veterinary Medicine, University College Dublin, Dublin, \\ Republic of Ireland
}

Submitted 17 August 2010: Accepted 25 February 2011: First published online 6 May 2011

\begin{abstract}
Objective: To investigate Irish consumers' use and understanding of and their belief in nutrition and health $(\mathrm{NH})$ claims in the context of the European Union (EU) legislation (Regulation no. 1924/2006), which permits a number of NH claims on food products.

Design: An interview-assisted questionnaire was administered to consumers ( $n$ 400). Preference for three types of NH claims across six products was tested. Perception of $\mathrm{NH}$ claims was assessed across a further eight food products. Claims were categorised as content, structure-function and disease-risk factor reduction claims.

Setting: Six supermarkets in the Republic of Ireland.

Subjects: Four hundred adult Irish supermarket consumers.

Results: Older $(P<0 \cdot 001)$, female $(P<0 \cdot 01)$ consumers were more likely to seek NH claims. Structure-function and content claims were preferred across six products. Consumers' perception was associated with the health benefit claimed rather than with the strength of the claim itself. Preference for claim type and claim perception differed with gender, age and educational level.

Conclusions: Irish consumers prefer content and simpler NH claims rather than more complex disease-risk factor reduction claims. The food industry may thus be better served using these types of claims. Although the reported levels of understanding were high, evidence of positivity bias and misinterpretation was found. Thus, with regard to Regulation 1924/2006, consumers need more information on both simpler and more complex claims. Public health messages should be targeted according to gender, age and educational level.
\end{abstract}

Keywords Nutrition claims Health claims Food labelling EU legislation
The European Union (EU) policy in the area of food and health has developed significantly in recent years and now includes legislation on nutrition and health $(\mathrm{NH})$ claims made on foods ${ }^{(1)}$ and a proposed new legislation on food and nutrition labelling ${ }^{(2)}$. The primary remit of NH claims Regulation 1924/2006 is with regard to consumers' protection $^{(1)}$.

$\mathrm{NH}$ claims are required to be comprehensible to the 'average consumer' as laid down in the regulation. The legislation defines the average consumer as 'reasonably well-informed and reasonably observant and circumspect, taking into account social, cultural and linguistic factors $^{(1)}$. However, there is no definitive test to determine the fulfilment of this condition. The European Food Safety Authority is not responsible for providing information on consumers' understanding ${ }^{(3)}$.

$\dagger$ Correspondence address: School of Medicine, Trinity Centre for Health Sciences, St James's Hospital, Dublin 8, Republic of Ireland.
Internationally, more research has been conducted on consumers' understanding and use of nutrition labelling ${ }^{(4,5)}$ than on consumers' understanding and use of $\mathrm{NH}$ claims. Some studies have shown that actual use of nutrition labels may be lower than reported, and some of the nutritional information provided is not well understood by consumers ${ }^{(6,7)}$. The limited research conducted on consumers' use and understanding of $\mathrm{NH}$ claims has shown that consumers are more likely to purchase products featuring NH claims than those without ${ }^{(8)}$. In a study conducted in France, 33\% of respondents reported this behaviour $^{(9)}$, whereas the Bureau Europeen des Unions des Consommatuers (BEUC) ${ }^{(10)}$ reported this figure as $>50 \%$. Leathwood et $a l^{(11)}$ highlighted the need for defining what constitutes adequate evidence to show consumers' understanding, as well as the need for both qualitative research to explore the different ways in which consumers may interpret a claim and quantitative research to measure the number of consumers who are able to show an understanding of claimed beneficial effects. 
The cross-national Internet-based survey of van Trijp and van der Lans ${ }^{(12)}$ showed that consumers' perception of $\mathrm{NH}$ claims varied across four countries as a function of five types of claims (content, structure-function, product, disease-risk factor reduction and marketing) and six health effects (CVD, stress, infection, fatigue, overweight and concentration). Other studies have found that it is the type of benefit that a product offers that is more influential, rather than the type of claim $^{(13-16)}$. However, van Trijp and van der Lans ${ }^{(12)}$ found that perception of benefit is influenced by familiarity with the ingredient and the natural link between the claim benefit and the carrier product (e.g. calcium- and milk-based products). Ford et $a l^{(17)}$ investigated consumers' behaviour when both a health claim and a nutrition label were read by participants. They hypothesised that, in the presence of a health claim, incorrect nutritional inferences may be made about the product in four possible ways: positivity bias consumers providing a higher estimation of the product in general; halo effect - consumers rating the product higher on other attributes not mentioned in the claim; magic bullet effect - consumers attributing inappropriate health benefits to the product; interactive effects - the degree of judgement bias influencing the degree to which nutritional information is ambiguous or unfavourable. Although their results did not support their hypothesis, evidence of positivity bias and halo effects has been reported in other studies ${ }^{(8,18,19)}$. Roe et $a l{ }^{(8)}$ showed that the presence of health claims and, to a lesser extent, of nutrient-content claims significantly increased the probability that respondents had ceased to search for further nutritional information.

The present study is the first of its kind in Ireland in which Irish consumers' preference for NH claims across six products and three claim types was evaluated. Demographic influence on the use and perception of $\mathrm{NH}$ claims was also investigated.

\section{Methods}

The questionnaire used in the present study, to determine the use and understanding of food labels, was initially piloted in one supermarket ( $n$ 30) and subsequently revised. A total of 821 consumers were then approached to participate in the survey, from six different urban/rural supermarket locations. Sampling was random, except for gender. Male consumers were targeted to achieve equal representation and to allow for comparative analysis. Day and time were alternated to ensure a representative sample. Interviewers were qualified dietitians ( $n 4)$, and willing consumers were invited to either self-complete or dictate their responses ${ }^{(20)}$. Questionnaires took approximately $15-20 \mathrm{~min}$ to complete. Ethical approval was obtained from the University of Ulster.

Participants were asked to select one claim from a choice of content, structure-function or disease-risk factor reduction claims for six products. Generic (non-branded), coloured pictures of these six products were used in an effort to avoid consumers' confusion between products. The range of statements was chosen to reflect both familiar and unfamiliar types of products and claims. For example, the fibre-containing cereal claim referred to 'fullness' rather than to the more commonly associated 'cancer prevention' benefit used to promote fibre. Similarly, the juice with soya proteins and the juice extracted from Chinese herbs were 'made up' products to test whether product familiarity had an impact on preference for claims. Participants were then asked to categorise NH claims as being believable, encouraging (i.e. would the $\mathrm{NH}$ claim encourage participants to buy the product?) or understandable for eight food products. 'Suggestive' claims (e.g. 'for a chaotic lifestyle'), which may not be governed by Regulation 1924/2006, were included to measure their impact. Demographic information was also collected.

Data were analysed using the Statistical Package for the Social Sciences statistical software package version $14 \cdot 0$ (SPSS Inc., Chicago, IL, USA). Non-parametric analyses ( $\chi^{2}$ tests) were performed in conjunction with descriptive statistics (frequency tables). Significance was defined using $P$ values $(P<0 \cdot 001, P<0 \cdot 01, P<0 \cdot 05)$.

\section{Results}

Of the 821 consumers invited to participate in the present survey, 408 participated and 400 surveys were completed, leading to a response rate of $49 \%$. Eight questionnaires were discarded as they were unfinished because participants ran out of time. More men than women declined to participate $(P<0 \cdot 05)$. Of the total sample of participants ( $n 400), 46 \%$ were men and $54 \%$ were women. Half were $<31$ years of age, whereas $55 \%$ had tertiary-level education (Table 1).

Consumers' food-purchasing practices are described in Table 2. The most common reasons cited for buying specific foods for a medical condition were the presence of high cholesterol ( $8 \%$ ) and heart disease (5\%). Of the $42 \%$ of participants who sought claims, 'General good health' (37\%) was the most widely reported reason for seeking $\mathrm{NH}$ claims, followed by high cholesterol or heart health $(35 \%)$ and increased body weight ( $9 \%)$. Women were significantly more likely to read food labels $(P<0 \cdot 001)$, be aware that claims exist $(P<0 \cdot 001)$ and seek claims $(P<0 \cdot 01)$. More educated consumers were significantly more aware of the existence of claims $(P<0 \cdot 01)$, whereas older consumers were significantly more likely to seek claims $(P<0 \cdot 001)$.

Table 3 shows the choice of statements representing content, structure-function and disease-risk factor reduction claims for six products. Consumers' preference for claim type varied across the six products (Table 4). For milk and calcium, and yoghurt and probiotics, a significant number of consumers preferred the structure-function claim over the other two types of claims $(P<0 \cdot 001)$. For spread and plant sterols, no significant difference was 
Table 1 Demographic profile of survey participants ( $n$ 400)

\begin{tabular}{lrr}
\hline & $n$ & $\%$ \\
\hline Gender & & \\
Male & 184 & 46 \\
Female & 216 & 54 \\
Age (years) & & \\
$<31$ & 199 & 50 \\
$31-50$ & 121 & 30 \\
$>50$ & 80 & 20 \\
Marital status & & \\
Single & 174 & 44 \\
Married & 148 & 37 \\
Co-habitating & 37 & 9 \\
Separated/divorced & 8 & 2 \\
Widowed & 9 & 2 \\
Other & 24 & 6 \\
Children (<18 years) & & \\
Yes & 94 & 24 \\
No & 306 & 77 \\
Educational level completed & & \\
Primary & 33 & 8 \\
Secondary & 86 & 22 \\
Training course (e.g. apprenticeship) & 64 & 16 \\
Tertiary level, undergraduate & 139 & 35 \\
Tertiary level, postgraduate & 78 & 20 \\
Occupation & & \\
Full-time employment & 244 & 61 \\
Regular part-time employment & 50 & 13 \\
Working from home & 9 & 2 \\
Seeking work & 21 & 5 \\
Student & 46 & 12 \\
Other & 30 & 8 \\
\hline & & \\
\hline
\end{tabular}

observed among participants with regard to preference for either content or health claim. For juice and Chinese herbs, there was no significant difference in preference between the content and structure-function claims; however, a significant number of participants preferred either a content or a structure-function claim over a disease-risk factor reduction claim $(P<0 \cdot 01)$. For cereal and fibre, a significant number of participants preferred a content claim over either a structure-function claim or a disease-risk factor reduction claim $(P<0 \cdot 001)$, whereas there was no significant difference in preference for a structure-function claim over a disease-risk factor reduction claim. In the case of juice and soya proteins, a significant number of participants preferred a content claim over the other two types of claims $(P<0 \cdot 001)$.

Content claims were the preferred option as participants' educational level increased (not illustrated), especially for yoghurt and probiotics, and spread and plant sterols $(P<0 \cdot 01)$. Female participants were more likely to choose disease-risk factor reduction claims for all products except cereal and fibre. Older women chose the disease-risk factor reduction claim type more often for the milk and calcium claim $(P<0 \cdot 001)$. The association of preference for the disease-risk factor reduction claim type with increased educational level varied across the six products and was significant for yoghurt and probiotics, spread and plant sterols, and juice and Chinese herbs $(P<0 \cdot 01)$. Structure-function claim wording was
Table 2 Determinants of food-purchasing practices ( $n$ 400)

\begin{tabular}{|c|c|c|}
\hline & $n$ & $\%$ \\
\hline \multicolumn{3}{|c|}{ Specific foods bought for a medical condition } \\
\hline Yes & 70 & 18 \\
\hline No & 330 & 83 \\
\hline \multicolumn{3}{|l|}{ Type of medical condition } \\
\hline No medical condition reported & 329 & 82 \\
\hline High cholesterol & 32 & 8 \\
\hline Heart disease & 19 & 5 \\
\hline Diabetes & 10 & 3 \\
\hline Digestion problems & 9 & 2 \\
\hline High blood pressure & 9 & 2 \\
\hline Joint problems & 7 & 2 \\
\hline Coeliac & 7 & 2 \\
\hline Milk/dairy allergy & 2 & 1 \\
\hline Asthma & 1 & $<1$ \\
\hline Anaemia & 1 & $<1$ \\
\hline Back pain & 1 & $<1$ \\
\hline \multicolumn{3}{|l|}{ Currently on a specific diet } \\
\hline Yes & 69 & 17 \\
\hline No & 331 & 83 \\
\hline \multicolumn{3}{|l|}{ Type of diet } \\
\hline None & 331 & 83 \\
\hline Healthy eating/balanced diet & 19 & 5 \\
\hline Cholesterol lowering/heart healthy & 10 & 3 \\
\hline Low fat & 10 & 3 \\
\hline Gluten free & 8 & 2 \\
\hline 'Weight Watchers' & 7 & 2 \\
\hline Weight control & 6 & 2 \\
\hline Reduced carbohydrate & 2 & 1 \\
\hline Wheat free & 1 & $<1$ \\
\hline Low sugar/low fat & 1 & $<1$ \\
\hline Vegetarian & 1 & $<1$ \\
\hline
\end{tabular}

significantly more likely to be chosen by younger participants than by older ones for yoghurt and probiotics $(P<0 \cdot 001)$, milk and calcium $(P<0 \cdot 01)$, spread and plant sterols $(P<0 \cdot 01)$ and cereal and fibre $(P<0 \cdot 05)$.

Table 5 shows participants' response to questions about whether the eight claims were perceived to be believable and understandable and whether they would encourage purchase. Overall, reported levels of understanding were high at 82-91\%, except for the multivitamin claim (69\%) and the skin-nourishing claim (54\%). Levels of belief were lower (except for the cereal claim) and more variable. Significantly more $(P<0 \cdot 001)$ women $(73 \%)$ than men $(51 \%)$ reported belief in the low-fat milk claim ('natural and nutritious'). Significantly more women than men also reported belief in the probiotic yoghurt $(P<0 \cdot 001)$ and apple drink $(P<0 \cdot 05)$ claims. For spread $(P<0 \cdot 05)$, cereal $(P<0 \cdot 01)$, low-fat milk $(P<0 \cdot 001)$ and apple drink $(P<0 \cdot 01)$, significantly more women than men reported that product statements would encourage them to purchase these products. More women than men (58\% v. 30\%) reported that the low-fat milk claim would encourage them to buy the product. Significantly more women than men reported understanding the cereal and skin-nourishing yoghurt product claims (both $P<0 \cdot 01$ ). For some claims, belief levels and encouragement to purchase levels were significantly associated with age; that is, 49\%, 55\% and $66 \%$ of those aged $<31,31-50$ and $>50$ years, respectively, were encouraged by the cholesterol-lowering spread claim 
Table 3 Participants were asked to select one option for each product in response to the question, 'Which of the following statements best describes the benefit of this product for you?'

\begin{tabular}{|c|c|}
\hline Product & Statement \\
\hline \multirow[t]{3}{*}{ Milk } & 'This milk contains calcium’^ \\
\hline & 'This milk helps build healthy bones because it contains calcium' $t$ \\
\hline & 'This milk may reduce the risk of osteoporosis because it contains calcium’ $\ddagger$ \\
\hline \multirow[t]{3}{*}{ Yoghurt } & "This yoghurt contains probiotics"* \\
\hline & 'This yoghurt helps strengthen the body's immune system because it contains probiotics't \\
\hline & 'This yoghurt may reduce the risk of gut infections because it contains probiotics' $\ddagger$ \\
\hline \multirow[t]{3}{*}{ Spread } & 'This spread contains plant sterols" \\
\hline & 'This spread helps lower LDL-cholesterol levels because it contains plant sterols'† \\
\hline & 'This spread may reduce the risk of CVD because it contains plant sterols' $\ddagger$ \\
\hline \multirow[t]{3}{*}{ Juice } & 'This juice contains Chinese herbs’* \\
\hline & 'This juice helps improve brain function because it contains Chinese herbs' $\dagger$ \\
\hline & 'This juice may decrease risk of a reduction in brain function because it contains Chinese herbs' \\
\hline \multirow[t]{3}{*}{ Cereal } & 'This cereal contains added fibre'* \\
\hline & 'This cereal keeps you feeling full because it contains added fibre' $\dagger$ \\
\hline & 'This cereal may reduce the risk of becoming overweight because it contains added fibre’ $\ddagger$ \\
\hline \multirow[t]{3}{*}{ Juice } & 'This fruit drink contains soya proteins"* \\
\hline & 'This fruit drink helps decrease allergies because it contains soya proteins' $\dagger$ \\
\hline & 'This fruit drink may decrease allergic reaction because it contains soya proteins’ł \\
\hline
\end{tabular}

${ }^{*}$ Content claim.

tStructure-function claim.

‡Disease-risk factor reduction claim.

Table 4 Preference for claim type across six products ( $n$ 400)

\begin{tabular}{|c|c|c|c|c|c|c|}
\hline & $\begin{array}{l}\text { Milk and } \\
\text { calcium }\end{array}$ & $\begin{array}{l}\text { Yoghurt and } \\
\text { probiotics }\end{array}$ & $\begin{array}{l}\text { Spread and } \\
\text { plant sterols }\end{array}$ & $\begin{array}{l}\text { Juice and } \\
\text { Chinese herbs }\end{array}$ & $\begin{array}{l}\text { Cereal and } \\
\text { fibre }\end{array}$ & $\begin{array}{l}\text { Juice and } \\
\text { soya proteins }\end{array}$ \\
\hline & $\%$ & $\%$ & $\%$ & $\%$ & $\%$ & $\%$ \\
\hline \multicolumn{7}{|l|}{ Content } \\
\hline 'Contains X' & 18 & 17 & 17 & 22 & 42 & 34 \\
\hline \multicolumn{7}{|l|}{ Structure-function } \\
\hline $\begin{array}{l}\text { 'Helps bodily function, } \\
\text { because it contains X' }\end{array}$ & 38 & 33 & $22+$ & 19 & 17 & 13 \\
\hline \multicolumn{7}{|l|}{ Disease-risk factor reduction } \\
\hline $\begin{array}{l}\text { 'Reduces risk of disease X, } \\
\text { because it contains X' }\end{array}$ & 26 & 11 & 22 & 14 & 18 & 17 \\
\hline
\end{tabular}

Values for Milk and calcium, Yoghurt and probiotics, Cereal and fibre and those for Juice and soya proteins are significantly different at $P<0.001$ and Juice and Chinese herbs at $P<0.05$, whereas values for Spread and plant sterols are non-significant.

tClassified as Article 14 claim in European Commission Regulation 1946/2006.

Table 5 Consumers' belief in encouragement perceived from and their understanding of eight claims

\begin{tabular}{|c|c|c|c|c|c|c|}
\hline \multirow[b]{3}{*}{ Product } & \multicolumn{2}{|c|}{ Believe } & \multicolumn{2}{|c|}{ Encourage } & \multicolumn{2}{|c|}{ Understand } \\
\hline & Yes & No & Yes & No & Yes & No \\
\hline & $\%$ & $\%$ & $\%$ & $\%$ & $\%$ & $\%$ \\
\hline Spread ('clinically proven to lower cholesterol') & 69 & 31 & 54 & 46 & 91 & 10 \\
\hline Probiotic yoghurt ('natural protection for your body') & 70 & 30 & 61 & 40 & 82 & 18 \\
\hline Whole-wheat cereal ('with added vitamins and iron') & 85 & 15 & 55 & 45 & 90 & 10 \\
\hline Low-fat milk ('natural and nutritious') & 63 & 37 & 46 & 54 & 87 & 14 \\
\hline Apple drink ('all natural; $100 \%$ juice') & 47 & 53 & 43 & 57 & 88 & 12 \\
\hline Milk chocolate ('a glass and a half of milk in every $200 \mathrm{~g}$ bar') & 59 & 42 & 17 & 83 & 88 & 12 \\
\hline Multivitamin ('for a chaotic lifestyle') & 47 & 53 & 28 & 72 & 69 & 31 \\
\hline Yoghurt ('nourish skin from the inside') & 23 & 77 & 13 & 87 & 54 & 46 \\
\hline
\end{tabular}

$(P<0 \cdot 05)$ and $57 \%, 56 \%$ and $76 \%$ of those aged $<31$, 31-50 and $>50$ years, respectively, were encouraged by the probiotic ('protection for the body') claim $(P<0 \cdot 01)$. Such an association was not reflected in the reported levels of understanding of claims $(P>0 \cdot 05)$.
Levels of belief in the probiotic yoghurt, apple drink and multivitamin statements decreased (all $P<0.05$ ) with an increase in educational level, whereas the opposite trend occurred for the chocolate claim $(P<0 \cdot 01)$. Participants' perception of claim persuasiveness for probiotic yoghurt, 
multivitamin and skin-nourishing yoghurt decreased with increasing educational level. Educational level was not associated with an understanding of claims $(P>0 \cdot 05)$.

In response to open-ended questions, only $14 \%$ reported understanding that the claim 'clinically proven to lower cholesterol' indicated that the product was 'heart healthy'. 'Aids immune system' was the explanation given by $37 \%$ of consumers for the 'natural protection for your body' probiotic yoghurt claim. The 'natural and nutritious' claim for low-fat milk was disbelieved by $22 \%$ of consumers, because they perceived the product to be less nutritious than the full-fat alternative. Consumers reported a high level of disbelief in the 'all natural; $100 \%$ juice' apple drink claim for reasons such as the likelihood of additives or preservatives (28\%), something unspecified (19\%) and sugar content (9\%). 'Negates the need for a balanced diet' was the explanation given for the 'for a chaotic lifestyle' multivitamin claim by $20 \%$ of consumers. Regarding the 'added vitamins and mineral' cereal claim, 2\% of consumers explained this claim as 'improves bone health'. The 'a-glass-and-a-half of milk in every $200 \mathrm{~g}$ bar' chocolate claim was explained by $17 \%$ of consumers as being 'higher in calcium' or that it 'contains milk, so good for you'.

\section{Discussion}

The present study involving a sample of Irish consumers has shown that, in general, consumers' perception of an $\mathrm{NH}$ claim depends on the specific claim benefit rather than on the strength of the claim itself, as set out in Regulation 1924/2006. For five out of six products, simpler claims (content, structure-function) were preferred over more technical disease-risk factor reduction (Article 14) claims. Overall, self-reported levels of belief in and understanding of $\mathrm{NH}$ claims were high, and were associated with product familiarity. Some consumers overestimated the potential benefits conveyed by $\mathrm{NH}$ claims.

The survey response rate of $49 \%$ is somewhat lower than the 'high' response rate of $63 \%^{(21)}$ reported by the North/South Ireland Food Consumption Survey (NSIFCS). However, unlike the latter study, participants in the present study had to be willing to complete the questionnaire 'then and there' upon being approached. In the present study, $67 \%$ of consumers reported reading food labels, which is higher than the NSIFCS reported figure of $48 \%{ }^{(21)}$. This is perhaps because all study participants were sampled in a supermarket, which is not representative of the whole population ${ }^{(6,18)}$, or because of over-reporting ${ }^{(5)}$. Women who were better educated examined food labels more often, which is widely reported in the literature ${ }^{(4,5,7,9,18)}$. Female gender, higher educational level and increased age were all positively associated with claim-seeking behaviour.

The results for preference of claim type concur with those of other studies ${ }^{(13,18,21,22)}$, which report consumers' preference for simpler, non-technical versions of claims. Results may reflect the high educational level $(50 \%$ had tertiary-level education) within this sample of consumers. However, research by the US Food and Drug Administration yielded similar results, showing that nutrient content claims have an impact similar to that of health claims $^{(8)}$. Other studies have also reported that preference for content claim type, rather than a stronger claim type, may also reflect increased familiarity with the health benefits of these nutrients ${ }^{(10,12,18,21)}$.

In the present study, disease-risk factor reduction claims were more influential when referring to familiar ${ }^{(21)}$ or serious ${ }^{(12,23)}$ diseases. Specifically, those citing 'osteoporosis' and 'CVD' were preferred to those citing 'gut infections', 'reduction in brain function' or 'overweight'. This agrees with the results of other studies ${ }^{(14)}$. In addition, preference for disease-risk factor reduction claims was associated with gender (women preferred this type of claim for milk and osteoporosis), which is shown elsewhere ${ }^{(21)}$, age (older participants preferred this type of claim for milk and calcium, and for yoghurt and probiotics) and educational level (most educated consumers preferred content claims). However, Urala et $a l^{(15)}$ reported no such association with either gender or age.

Participants' belief in NH claims was associated with product benefit rather than with claim strength. A cholesterollowering spread containing plant sterols with the claim 'clinically proven to lower cholesterol' was used as an example of a disease-risk factor reduction claim, which is classified as Article 14. Reported belief in this claim was high at $69 \%$, which may reflect consumers' familiarity, extensive advertising and increased heart-health awareness. Reported understanding was also high at $91 \%$. However, the mechanism of plant sterol action is poorly understood $^{(13)}$ and consumers may be overestimating their understanding as discussed by BEUC ${ }^{(10)}$. 'Heart healthy' was cited by $14 \%$ of consumers in their self-explanation of the claim, which would support the argument to categorise such claims as Article 14. The perceived encouraging (encourage to buy) nature of the claim is the feature rated the second highest among the eight products, which agrees with available literature that disease-risk factor reduction claims are more influential on intent to purchase than are weaker claim types ${ }^{(18)}$.

Consumers perception of two different structurefunction (Article 13.5) claims varied depending on product familiarity and specific benefit. Belief in the probiotic yoghurt-drink claim ('natural protection for your body') was higher than belief in the skin-enhancing yoghurt claim ('nourish the skin from the inside'). The carrier product (yoghurt) is similar ${ }^{(12)}$, and both claims are short and simple ${ }^{(24)}$. However, as reported by others, lack of familiarity and the perceived importance of an immunity $v$. a cosmetic benefit ${ }^{(25)}$ may have had an influence on the levels of consumers' belief. Understanding of the probiotic yoghurt claim was also higher than that of the 
skin-enhancing yoghurt claim. Consumers used the terms 'immune system', 'bacteria' and 'gut/digestion' to explain the probiotic yoghurt, which may be interpreted as the 'halo effect' as described by Ford et al. ${ }^{(17)}$.

Content claims for whole-wheat cereal 'with added vitamins and iron' and 'Apple Splash' fruit juice that is 'all natural, 100\% juice' were reportedly understood by almost all consumers. However, although a majority reported belief in the claim for whole-wheat cereal, $<50 \%$ reported belief in apple drink. Only $63 \%$ of consumers reported belief in the non-specific statement 'natural and nutritious' for low-fat milk. This is somewhat surprising given the promotion of low-fat dairy products by health agencies ${ }^{(26)}$ and the increased concern of consumers with regard to the fat content of foods ${ }^{(25)}$. Interestingly, $7 \%$ mentioned cholesterol and heart health in their explanation of the claim. This corresponds with conclusions drawn by van Trijp and van der Lans ${ }^{(12)}$ that state that consumers do not differentiate between types of claims.

Other statements included in the present study were for a chocolate product ('a glass and a half of milk in every $200 \mathrm{~g}$ bar') and a probiotic multivitamin product ('for a chaotic lifestyle'). In all, $17 \%$ of consumers attributed mostly incorrect health benefits to the chocolate product ('higher in calcium' or 'contains milk, so good for you'), whereas 34\% did so for the multivitamin product ('keeps you healthy', 'aids immune system', 'aids digestive system' or 'negates the need for a balanced diet') because of the mere presence of a claim ${ }^{(17)}$. Research remains inconclusive as to whether the presence of NH claims affects consumers' processing of nutritional information ${ }^{(20)}$. This may provoke thought as to whether Regulation 1924/2006 should be extended to govern such suggestive claims.

A greater number of women than men reported belief in, encouragement to buy and understanding of claims. Other researchers have reported increased female consciousness about health and increased familiarity with food products $^{(21)}$. Educational level was not associated with claim understanding, which was reported by Mitra et $a l^{(27)}$.

It is important to note the limitations of the present study, which include: the over-representation of consumers with tertiary-level education; the small number of health benefits tested; the potential for confounding variability as consumers evaluated claims consecutively; and inter-product variability as a standardised base product was not used. Furthermore, the present study was a survey of participants' preference for and opinion of $\mathrm{NH}$ claims and did not represent actual purchasing decisions.

The primary remit of Regulation 1924/2006 is consumers' protection. The present study highlights the powerful influence of $\mathrm{NH}$ claims on consumers' attitudes and understanding of $\mathrm{NH}$ claims by the 'average' consumer in Ireland. The results may provide 'food for thought' for legislators, industry and public health educators. Regulation 1924/2006 emphasises the categorisation of $\mathrm{NH}$ claims. However, this research found that consumers do not make such a distinction and are receptive to varying $\mathrm{NH}$ claim formulations. This is of relevance to the current claim-processing activities of the EU as consumers clearly need more information on both simpler and more complex claims.

Public health messages should be pitched appropriately according to gender, age and educational level. Examples could include: television advertising aimed at different male and female age groups during appropriate programming schedules; advertising on Internet websites including social networking sites; downloadable smartphone applications; and initiatives in community groups and health promotion departments. Nutritional education should be included in school curricula and integrated across various subjects; for example, fractions and portion size, percentages and fat content of foods, geography and food miles.

Additional research is necessary to further delineate objective methods of assessing the impact of $\mathrm{NH}$ claims on consumers' food-purchasing practices and to provide evidence at an international level on the impact of $\mathrm{NH}$ claims on consumers' food choices. Cultural differences exist both internationally and within the twenty-seven EU member states, which suggests that a 'one size fits all' approach may be difficult to achieve.

\section{Acknowledgements}

The present research received no specific grant from any funding agency in the public, commercial or not-for-profit sectors. The authors have no conflict of interest to declare. The present study was undertaken as partial fulfilment of the requirement for the degree of MSc European Food Regulatory Affairs (University of Ulster). The study was designed by A.-M.L. and A.M.K.; data were collected and analysed by A.-M.L. under the supervision of A.M.K.; the manuscript was written by A.-M.L., with contributions from A.-M.K. and M.J.G. The authors extend their gratitude to Dr Sarah Burke (Food Safety Authority Ireland) for her advice on data analysis and to all who participated in and supported this work.

\section{References}

1. European Parliament and Council (2006) Regulation (EC) No 1924/2006 of the European Parliament and of The Council of 20 December 2006 on nutrition and health claims made on foods. OJ L404 49, 9-25.

2. European Union (2008) Questions and answers on food labelling. Europa press release, 30 January. http:// europa.eu/rapid/pressReleasesAction.do? reference $=\mathrm{MEMO} / 08 /$ $64 \&$ format $=$ HTML\&aged $=0$ \&language $=\mathrm{EN} \&$ guiLanguage $=\mathrm{en}$ (accessed September 2009).

3. European Food Safety Authority (2010) Technical meeting with stakeholders on recent developments related to health claims. http://www.efsa.europa.eu/en/events/event/nda 100601.htm (accessed July 2010).

4. Grunert KG, Fernandez-Celemin L, Wills JM et al. (2009) Use and understanding of nutrition information on food labels in six European countries. J Public Health 18, 261-277. 
5. Cowburn G \& Stockley L (2005) Consumer understanding and use of nutrition labelling: a systematic review. Public Health Nutr $\mathbf{8}, 21-28$.

6. European Heart Network (2003) A Systematic Review of the Research on Consumer Understanding of Food Labelling. Brussels: European Heart Foundation; available at http:// www.ehnheart.org/files/consumer\%20nutrition-143058A.pdf

7. Shine A, O'Reilly S \& O'Sullivan K (1997) Consumer use of nutrition labels. Br Food J 99, 290-296.

8. Roe BE, Levy AS \& Derby BM (1999) The impact of health claims on consumer search and product evaluation outcomes. Results from FDA experimental data. J Public Policy Mark 18, 89-115.

9. Consommation Logement et Cadre de Vie (2004) Convention A02/22 relative a l'etude de la comprehension par les consummateurs de certaines mentions figurant dans l'etiquetage des denrees alimentaires preambelees et a leur perception de certains allegations nutritionelles, fonctionnelles et de sante. Paris: CLCV/DGAL. In Gunert KG \& Wills JM (2007) A review of European research on consumer response to nutrition information on food labels. J Public Health 15, 385-399.

10. Bureau Europeen des Unions des Consommatuers (2006) Health claims can be bad for you. http://docshare.beuc. org/docs/6/JIDECKDBOAHCALPFMEDOIJFLPDBN9DBYA 69DW3571KM/BEUC/docs/DLS/2006-00233-01-E.pdf (accessed April 2007).

11. Leathwood PD, Richardson DP, Strater P et al. (2007) Consumer understanding of nutrition and health claims: sources of evidence. BrJ Nutr 98, 474-484.

12. van Trijp HCM \& van der Lans IA (2007) Consumer perceptions of nutrition and health claims. Appetite $\mathbf{4 8}$, 305-324.

13. Food Standards Agency (2002) Health claims on food packaging: consumer-related qualitative research. Forum Qualitative for COI for FSA. http://www.foodstandards.gov. uk/multimedia/pdfs/healtclaims.pdf (accessed March 2007).

14. Bech-Larsen $T$ \& Grunert KG (2003) The perceived healthiness of functional foods: a conjoint study of Danish, Finnish and American consumers' perception of functional foods. Appetite 40, 9-14.
15. Urala N, Arvola A \& Lahteenmaki L (2003) Strength of health-related claims and their perceived advantage. Int J Food Sci Technol 38, 815-826.

16. Williams P (2005) Consumer understanding and use of health claims for foods. Nutr Rev 63, 256-264.

17. Ford GT, Hastrak M, Mitra A et al. (1996) Can consumers interpret nutritional information in the presence of a health claim? A laboratory investigation. J Public Policy Mark 15, $16-27$.

18. Shine A, O'Reilly S \& O'Sullivan K (1997) Consumer attitudes to nutrition labelling. Br Food J 99, 283-289.

19. Andrews JC, Netemeyer RG \& Burton S (1998) Consumer generalisation of nutrient content claims in advertising. J Mark 62, 62-75.

20. Baltas G (2001) Nutrition labelling: issues and policies. Eur J Mark 35, 708-721.

21. Irish Universities Nutrition Alliance (2001) North/South Ireland Food Consumption Survey. http://www.iuna.net/ documents/Food\%20Survey\%202001.pdf (accessed June 2007).

22. Bruhn CM, Bruhn JC, Cotter A et al. (2002) Consumer attitudes toward use of probiotic cultures. J Food Sci 67 , 1969-1972.

23. van Kleef E, van Trijp HCM \& Lunning P (2005) Functional foods: health claim-food compatibility and the impact of health claim framing on consumer evaluation. Appetite $\mathbf{4 4}$, 299-308.

24. Wansink B, Sonka ST \& Hasler CM (2004) Front-label health claims: when less is more. Food Policy 29, 659-667.

25. Garretson JA \& Burton S (2000) Effects of nutrition facts panel values, nutrition claims and health claims on consumer attitudes perceptions of disease-related risks and trust. J Public Policy Mark 19, 213-227.

26. Irish Heart Foundation (2007) Nutrition guidelines for heart health with policy recommendations. Dublin, May 2007. http://www.irishheart.ie/iopen24/pub/positionstatements/ final_nutrition_guidelines2007.pdf (accessed August 2007).

27. Mitra A, Hastak M, Ford GT et al. (1999) Can the educationally disadvantaged interpret the FDA-mandated nutrition facts panel in the presence of an implied health claim. J Public Policy Mark 18, 106-117. 